\title{
The Risk of Cesarean Delivery in Short Saudi Women
}

\author{
Nourah H. Al Qahtani, Salha Al Ganmi, Asma Badran \\ Department of Obstetrics and Gynecology, College of Medicine, University of Dammam, Dammam, Saudi Arabia. \\ Email: \{dr.nourah, asmabadran\}@gmail.com,dr_alghanimi@hotmail.com
}

Received January $18^{\text {th }}, 2012$; revised February $24^{\text {th }}$, 2012; accepted March $12^{\text {th }}, 2012$

\begin{abstract}
Objectives: To evaluate the relationship between maternal height of $<155 \mathrm{~cm}$ and the risk of caesarean delivery due to failure to progress (FTP) among nulliparous saudi women. Design: Observational cohort study. Material and Method: A total of 405 term (GA > 37 weeks), uncomplicated singleton nulliparous pregnant women were enrolled on admission to labour room. The patients were divided into two groups based on maternal height, $>155 \mathrm{~cm}$ (247 cases) as control and $<155 \mathrm{~cm}$ (158 cases) as study group. The medical records of these women were reviewed. Various baseline clinical characteristics were collected. Maternal characteristics and maternal and neonatal outcomes were recorded. Results: Caesarean section rate for all indications was higher among study group than control group (26.6\% and $19.4 \%$ respectively, $\mathrm{p}=0.023)$. Significant difference was observed in the rate of caesarean delivery due to failure to progress $(7.3 \%$ and $12 \%$ in control and study group respectively, p-value 0.038 ). The rate of caesarean delivery due to failure to progress was highest among those with height $150-155 \mathrm{~cm}$ (p-value 0.022). Mean birth weight was significantly higher among control group than study group ( $3137 \pm 403 \mathrm{~g}$ and $3030 \pm 408$ respectively, p-value 0.010$)$. Conclusion: Term singleton nulliparous Saudi pregnant women with maternal height $151-154 \mathrm{~cm}$ were associated with a greater likelihood of caesarean section for failure to progress. Women with height $<150 \mathrm{~cm}$ did not have increased cesarean section rate. However, mean birth weight was significantly lower in this group.
\end{abstract}

Keywords: Maternal Height; Cesarean Delivery; Failure to Progress

\section{Introduction}

Failure to progress is a common cause for performing elective or emergency Cesarean section. The term "failure to progress" has been used to describe lack of progressive cervical dilatation or lack of descent of fetal head or both. The active phase of labor begins at a cervical dilatation of 3 to $4 \mathrm{~cm}$ or more, and its onset is considered to be a reasonably reliable diagnostic threshold of active labor because it demarcates the transition from desultory progression in the latent phase to more rapid cervical dilatation. In addition, the American College of Obstetricians and Gynecologists has proposed that the performance of cesarean delivery for dystocia be specifically indicated only in women in the active phase of labor [1]. Obstructed labour remains one of the most important causes of maternal mortality in developing countries and failure to progress is the leading cause of both operative vaginal delivery and caesarean delivery and their accompanying complications [2,3]. Various methods have been employed for the prediction of FTP, including maternal height, paternal height, maternal and paternal head circumference, maternal shoe size and different pelvi-metric measurements.

There is a numbers of studies [4-9] that have reported correlation between maternal height and assisted delivery, i.e. forceps extraction, Caesarean section, while others $[10,11]$ have failed to find such correlation. These studies were conducted in different populations with different cut-off points for labeling the lady as having short stature. Maternal height, which is easy to measure, has been reported to be a useful tool to predict difficult childbirth and FTP. Maternal height of $<155 \mathrm{~cm}$ has been reported as an obstetric risk factor for dystocia due to FTP, and thus for caesarean section. In addition, several studies found maternal short stature to be associated with adverse perinatal outcomes including low birth weight and neonatal asphyxia. The present study was aimed to evaluate the relationship between maternal height of $<155 \mathrm{~cm}$ and the risk of caesarean delivery due to FTP among Saudi women admitted for delivery in King Fahed University hospital. In addition, pregnancy outcomes were also evaluated.

\section{Material and Methods}

A retrospective cohort study was conducted at King Fahed University Hospital. A total of 405 term (gestational age $>37$ weeks), uncomplicated singleton nulliparous pregnant women between January 2006 to January 
2009 were enrolled on admission to labour room. The patients were divided into two groups, i.e. 158 mothers with height of $<155 \mathrm{~cm}$ (Study group) and 247 mothers with height of $155 \mathrm{~cm}$ or more (Control group). Mothers who are exactly $155 \mathrm{~cm}$ tall were included in the control group. Controls were randomly selected from pregnant women who were admitted in the same day as women in the study group. Exclusion criteria included pregnancy with medical or obstetric complications, those with nonvertex presentation of the fetus, those with fetal anomaly or fetal death, and those who were indicated for elective caesarean section, e.g., placenta previa, previous uterine scar and intrauterine growth restriction. The medical records of these pregnant women were reviewed. Various baseline clinical characteristics were collected. Maternal and neonatal outcomes were recorded. Failure to progress was defined as no cervical dilatation during the active phase of labor for at least $2 \mathrm{hr}$ or no descent of the fetus's head during the second stage of labor for at least 1 hr despite adequate uterine contraction. This was considered an indication for cesarean delivery for failure to progress. Univariate analysis was used to compare various characteristics between the two groups, either by Chi-square test, fisher exact test or Student's t test as appropriate. $\mathrm{P}$ value of less than 0.05 was considered of statistical significance.

\section{Results}

During the study period, a total of 405 nulliparous pregnant women who met the criteria, were enrolled: 158 in study group and 247 in the control group. Table 1 shows comparison of baseline characteristics between the two groups. Both groups were comparable with regard to age, gestational age and body mass index.

Table 2 shows comparison of the route of delivery between the two groups when caesarean section was stratified by its indication. No significant difference was observed in the rate of caesarean delivery due to FTP (12\% and $7.3 \%$ in study and control group respectively, $\mathrm{p}$ $=0.376$ ). Comparison of neonatal characteristics was shown in Table 3. Mean birth weight was significantly lower in the study group than in the control group (3030 $\pm 408 \mathrm{~g}$ and $3137 \pm 403 \mathrm{~g}$ respectively, $\mathrm{p}<0.010$ ). Low birth weight $(<2500 \mathrm{~g})$ was similar in both groups. No birth asphyxia was observed in both groups.

When maternal height was reclassified in to 3 groups; $<150 \mathrm{~cm}$ (51 women), $151-154 \mathrm{~cm}$ (107 women), and > $155 \mathrm{~cm}$ (247 women), significant differences in caesarean delivery due to FTP were observed as shown in Table 4. The rate of caesarean delivery due to FTP was highest among those with height $151-154 \mathrm{~cm}$ while the rates in the other 2 groups were comparable. Pregnant women shorter than $150 \mathrm{~cm}$ have significantly lower fetal birth weight (Figure 1).
Table 1. Baseline characteristics of pregnant women.

\begin{tabular}{lccc}
\hline \multicolumn{1}{c}{ Characteristics } & $\begin{array}{c}\text { Control group } \\
(\mathrm{n}=247)\end{array}$ & $\begin{array}{c}\text { Study group } \\
(\mathrm{n}=158)\end{array}$ & p-value \\
\hline Mean age \pm SD (years) & $23.6 \pm 4.3$ & $23.8 \pm 4.5$ & 0.086 \\
$\begin{array}{l}\text { Mean gestational age } \pm \text { SD } \\
\text { (weeks) }\end{array}$ & $39.5 \pm 1.24$ & $39.3 \pm 1.32$ & 0.094 \\
Body Mass Index & $28.77 \pm 5.28$ & $29.28 \pm 5.58$ & 0.131 \\
\hline
\end{tabular}

Table 2. Route of delivery.

\begin{tabular}{lccc}
\hline \multicolumn{1}{c}{ Route of delivery } & $\begin{array}{c}\text { Control group } \\
(\mathrm{n}=247)\end{array}$ & $\begin{array}{c}\text { Study group } \\
(\mathrm{n}=158)\end{array}$ & $\mathrm{p}$-value \\
\hline Vaginal delivery & 199 & 116 & 0.02 \\
Vaccum delivery & 6 & 4 & 0.25 \\
$\begin{array}{l}\text { Cesarean section due to FTP } \\
\begin{array}{l}\text { Cesarean section due to } \\
\text { fetal distress }\end{array}\end{array}$ & 18 & 19 & 0.038 \\
\hline
\end{tabular}

Table 3. Neonatal outcome.

\begin{tabular}{lccc}
\hline \multicolumn{1}{c}{ Neonatal outcome } & $\begin{array}{c}\text { Control group } \\
(\mathrm{n}=247)\end{array}$ & $\begin{array}{c}\text { Study group } \\
(\mathrm{n}=158)\end{array}$ & $\mathrm{p}$-value \\
\hline Mean birth weight \pm SD (gm) & $3137 \pm 403$ & $3030 \pm 408$ & 0.010 \\
Low birth weight $(>2500)$ & $2(1 \%)$ & $3(1.8 \%)$ & 0.221 \\
\hline
\end{tabular}

Table 4. Rate of cesarean section due to FTP among different maternal height.

\begin{tabular}{ccc}
\hline Maternal height & $\begin{array}{c}\text { Rate of cesarean section due to FTP. } \\
\text { N/Total (\%) }\end{array}$ & p-value \\
\hline$<151 \mathrm{~cm}$ & $4 / 51(7.8 \%)$ & 0.89 \\
$151-155$ & $15 / 107(14 \%)$ & 0.022 \\
$>155$ & $18 / 247(7.3 \%)$ & 0.222 \\
\hline
\end{tabular}

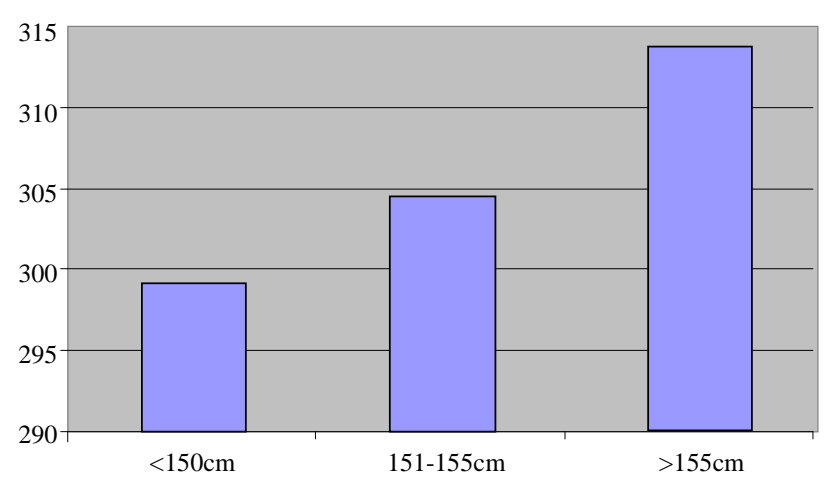

Figure 1. Birth weight in the three groups according to maternal height. 


\section{Discussion}

Maternal height, which is easy to measure, has been reported to be a useful tool to predict difficult childbirth and failure to progress [6-12]. There is conflicting results in the literature regarding the association between the short stature and the risk of cesarean section, some reporting significant increase in the rate of cesarean section in short mothers while other studies reporting no significant difference. One of the reasons for these differences might be because these studies are using different cut-off points for the definition of short stature. The cut-off point most commonly used by many authors range from 152 $155 \mathrm{~cm}$. However, there was one study using $>140 \mathrm{~cm}$ as the definition of short stature in Saudi women [13]. This might be appropriate cut off point in Asian populations. The studies with higher cut-off points are mainly done in America, Europe and Africa where the average height for these populations are higher than our population. Previous studies have reported that maternal short stature was an independent risk factor for caesarean delivery regardless of its association to dystocia, a major cause for caesarean delivery among short parturient women [14].

In this study, significant association was observed between maternal short stature $(<155 \mathrm{~cm})$ and the rate of caesarean section due to failure to progress. Higher cesarean section rate was observed among short stature mothers $(12 \%$ and $7.3 \%$ in study and control groups, respectively, p-value 0.038). But when maternal height was reclassified, it was found that cesarean section rates due to FTP increased significantly among women who were $151-154 \mathrm{~cm}$ tall. While those who are $<150 \mathrm{~cm}$ did not have increased rate of cesarean section compared to the control group $(7.3 \%$ and $7.8 \%$ in control and $<150$ $\mathrm{cm}$ group, respectively). This could be due to the significantly lower birth weight among this group compared to the study group (2992 gm and $3137 \mathrm{gm}$ in the control and the $<150 \mathrm{~cm}$ group, respectively).

Some studies have reported that some adverse perinatal outcomes were associated with maternal short stature, including low birth weight and neonatal asphyxia [15-18]. These findings were not confirmed in this study. In this study, significantly lower mean birth weight among mothers with short stature has been observed but might be without clinical significance (difference of $100 \mathrm{~g}$ ). In addition, low birth weight was similar among mothers with short stature and control group. However, no birth asphyxia was found in any newborn. There was no significant difference in the Body mass index between the control and the study group (28.77 and 29.28 in the control and the study group, respectively). However, when pregnant women were reclassified into two groups according to their BMI, there was significant difference in the rate of cesarean section due to FTP. Laboring women with body mass index of $>26$ have $12.1 \%$ rate of Cesar- ean section and those of BMI of $<26$ were $5.2 \%$ (p-value 0.014).

The limitation of our study included minor errors that are inevitable due to the nature of retrospective data. Some information might not be accurate and some mothers might be misclassified due to inaccuracy of their recorded height. However, such errors should only be minimal. In addition, we did not know if mothers who underwent caesarean section from other indications than FTP actually had FTP or not since caesarean section due to fetal distress could have taken place before FTP could be diagnosed. In addition, data on other factors related to FTP such as pelvimetry were not available.

More data about the anthropometric measurement in the Saudi pregnant women is needed to establish the normal distribution of maternal height in our population. It can not be overestimated that we can not use cut-off point for the definition of stature based on other populations. Because the likelihood of having a normal vaginal delivery was still very good, maternal height alone should not affect the management of labour and decision on route of delivery, especially very short pregnant women as they tend to have smaller babies. However the combination of other risk factors with maternal height may be of more clinical use in the management and decision-making process of laboring women.

\section{REFERENCES}

[1] American College of Obstetricians and Gynecologists, “ACOG Technical Bulletin No. 218," American College of Obstetricians and Gynecologists, Washington DC, 1995.

[2] World Health Organization, "Maternal Mortality: A Global Factbook,” Division of Family Health, Geneva, 1991.

[3] American College of Obstetricians and Gynecologists, "ACOG Practice Bulletin No. 102: Clinical Management Guidelines for Obstetrician Gynecologists,” 2003, pp. 14451454.

[4] S. Kirchengast and B. Hartmann, "Short Stature Is Associated with an Increased Risk of Caesarean Deliveries in Low Risk Population,” Acta Medica Lituanica, Vol. 14, No. 1, 200, pp. 1-6

[5] K. M. Merchanta, J. Villarb and E. Kestler, "Maternal Height and Newborn Size Relative to Risk of Intrapartum Caesarean Delivery and Perinatal Distress,” British Journal of Obstetrics and Gynaecology, Vol. 108, No. 7, 2001, pp. 689-696

[6] A. Rozenholc, S. Ako, R. Leke and M. Boulvain, "The Diagnostic Accuracy of External Pelvimetry and Maternal Height to Predict Dystocia in Nulliparous Women: A Study in Cameroon," International Journal of Obstetrics and Gynaecology, Vol. 114, No. 5, 2007, pp. 630-635. doi:10.1111/j.1471-0528.2007.01294.X

[7] World Health Organization, "Maternal Anthropometry and Pregnancy Outcomes. A WHO Collaborative Study,” WHO Bulletin, Vol. 73, 1995, pp. 1-69. 
[8] W. N. Ogala and L. Audu, "Predicting Conception and Safe Delivery of a Macrosomic Baby," Central African Journal of Medicine, Vol. 42, No. 11, 1996, pp. 316-319.

[9] L. Turcot, S. Marcoux, W. D. Fraser, "Multivariate Analysis of Risk Factors for Operative Delivery in Nulliparous Women," American Journal of Obstetrics and Gynecology, Vol. 176, No. 2, 1997, pp. 395-402. doi:10.1016/S0002-9378(97)70505-2

[10] N. Wongcharoenkiat and D. Boriboonhirunsarn, "Maternal Height and the Risk of Cesarean Delivery in Nulliparous Women," Journal of the Medical Association of Thailand, Vol. 89, Suppl. 4, 2006, pp. S65-S69.

[11] B. J. McGuinness and A. N. Trivedi, "Maternal Height as a Risk Factor for Caesarean Section Due to Failure to Progress in Labour," The Australian and New Zealand Journal of Obstetrics and Gynaecology, Vol. 39, No. 2, 1999, pp. 152-154. doi:10.1111/j.1479-828X.1999.tb03360.x

[12] B. Möller and G. Lindmark, "Short Stature: An Obstetric Risk Factor? A Comparison of Two Villages in Tanzania," Acta Obstetricia et Gynecologica Scandinavica, Vol. 76, No. 5, 1997, pp. 394-397. doi:10.3109/00016349709047817

[13] T. J. Hashim and S. A. Moawed, "The Relation of Low Birth Weight to Psychosocial Stress and Maternal Anthropometric Measurements," Saudi Medical Journal, Vol.
21, No. 7, 2000, pp. 649-654.

[14] L. Brabin, F. Verhoeff and B. J. Brabin, "Maternal Height, Birhtweight and Cephalo-Pelvic Disproportion in Urban Nigeria and Rural Malawi," Acta Obstetricia et Gynecologica Scandinavica, Vol. 81, No. 6, 2002, pp. 502-507. doi:10.1034/j.1600-0412.2002.810605.x

[15] A. P. Camilleri, "The Obstetric Significance of Short Stature,” European Journal of Obstetrics \& Gynecology and Reproductive Biology, Vol. 12, No. 6, 1981, pp. 347-356. doi:10.1016/0028-2243(81)90080-0

[16] D. Sokal, L. Sawadogo and A. Adjibade, "Short Stature and Cephalo-Pelvic Disproportion in Burkina Faso West Africa," International Journal of Gynecology \& Obstetrics, Vol. 35, No. 4, 1991, pp. 347-350. doi:10.1016/0020-7292(91)90671-Q

[17] B. J. McGuinness and A. N. Trivedi, "Maternal Height as a Risk Factor for Cesarean Section Due to Failure to Pregress in Labou," Australian and New Zealand Journal of Obstetrics and Gynaecology, Vol. 39, No. 2, 1999, pp. 152154. doi:10.1111/j.1479-828X.1999.tb03360.X

[18] K. M. Merchant, J. Villar and E. Kestler, "Maternal Height and Newborn Size Relative to Risk of Intrapartum Caesarean Delivery and Perinatal Distress,” International Journal of Obstetrics and Gynaecology, Vol. 108, No. 7, 2001, pp. 689-696. 